\title{
RASGOS FONÉTICOS HALLADOS EN UNAS ACTAS CAPITULARES LUCENTINAS DEL SIGLO XVII (1600-1617)
}

\author{
Ana Isabel Pérez Cruz \\ Universidad de Granada \\ anabelf@correo.ugr.es
}

\begin{abstract}
Resumen
En las siguientes páginas analizaremos la lengua, en especial, la fonética en el siglo XVI a través de las Actas Capitulares (1600-1617) de Lucena, ciudad del sur de Córdoba. Este lugar es interesante porque en nuestros días su población sesea y aspira la /-s/ implosiva. Por esta razón elegimos estos documentos y estudiamos veinte sesiones. Muestran seseos y la citada aspiración. También, podemos encontrarnos con otros fenómenos: vacilación entre b y v, vacilación a la hora de la articulación de ciertos grupos consonánticos (/-ct-/,/-cp-/ o (-mn-) y, finalmente vacilaciones entre vocales $/ \mathrm{e} / \mathrm{e} / \mathrm{i} / \mathrm{e}$, incluso, $/ \mathrm{o} / \mathrm{y} / \mathrm{u} /$, respectivamente. Pensamos que muchas de estos rasgos fonéticos fueron llevados al Reino de Granada porque en Lucena tuvo lugar una importante batalla en la que Boabdil en 1483 fue apresado por Diego Fernández de Córdoba. Es difícil llegar a la conclusión de que en el siglo XVII toda la población lucentina seseara o aspirara la /-s/ implosiva debido a que las citadas actas fueron escritas por diversos escribanos que no mostraban esta pronunciación. No obstante, los ejemplos hallados son una prueba importante para conocer parte de la lengua en la citada centuria.
\end{abstract}

PALABRAS CLAVE: Fonética, historia, Siglo Oro, Lucena, seseo.

\begin{abstract}
In the following pages we analyze the language, in special, the phonetic in the seventeenth century through the Actas Capitulares (1600-1617) of Lucena, town in the South of Córdoba (Spain). This place is interesting because in our days its population pronounces in a special way, for instance, we can find in them seseo (they pronounce Spanish $/ \theta /$ like $/ \mathrm{s} /$ ) or we notice the weak pronounciation of $/ \mathrm{s} /$ in most words. For this reason, we choose these documents, Actas Capitulares and we study twenty two sessions of these documents. They show seseos and the absence of $/-\mathrm{s} /$ in the seventeenth century. Also, we can find in these papers other phonetic cases like: doubts between $/ \mathrm{b} /$ and $/ \mathrm{v} /$, doubts in the use of many groups of consonants (/-ct-/, $/ \mathrm{cp}-/$ or $/-\mathrm{mn}-/)$ and, finally, doubts in the use of many vowels like /e/ or $/ \mathrm{i} /$, even $/ \mathrm{u} /$ or $/ \mathrm{o} /$. We think many of these phonetic cases were taken to the Kingdom of Granada because an important battle took place in Lucena, in 1483, in which Boabdil was captured by Diego Fernández de Córdoba.

It's difficult to conclude that in the seventeenth century there was seseo or weak pronounciation of $/$-s/ in all the population from Lucena because these Actas Capitulares were written by different people who didn't have this pronounciation at all. But, the found examples are an important clue to know that this pronounciation exists in this century.
\end{abstract}

KEY WORDS: Phonetica, Golden Century, Lucena, Mistakes s/c.

En el presente trabajo vamos a estudiar algunos aspectos de la fonética perteneciente a las Actas Capitulares de Lucena (Córdoba) ubicadas en el Archivo Municipal de dicha ciudad. Se trata de unos documentos que datan del siglo XVII, concretamente analizaremos fonéticamente el período comprendido entre 1600 y 1617 en el que se establecen unas veintidós sesiones incluidas en las mencionadas actas. Hemos indicar que la documentación con la que trabajamos es original e inédita, no hemos empleado copias. 
Es importante que antes de adentrarnos en este estudio fonético dejemos clara la división que vamos a realizar de dichas sesiones para clasificar los fenómenos hallados. De este modo, diremos que en las Actas Capitulares estudiadas hallamos diferentes escrituras, distintos tipos de procesales y humanísticas, que revelan la presencia de diferentes manos. Hemos de indicar que no son válidas las rúbricas de los diferentes escribanos para adjudicarles uno de ellos a cada tipo de escritura puesto que si se cotejan las grafías de las citadas rúbricas con las grafías presentes en los documentos se advierte que no hay ningún parecido. Incluso, hemos de señalar que en distintos documentos con diferentes grafías figura la misma rúbrica. Llegamos, pues a la conclusión de que los documentos serían escritos por amanuenses cuyo nombre no figura y firmados por escribanos como: Jerónimo de Morales, Cristóbal de Morales o Luis de Morales.

Así pues, la división que realizaremos para analizar los fenómenos fonéticos será la siguiente: Consideraremos las veintidós sesiones según la tipología de escritura que presenten teniendo en cuenta también la fecha en la que fueron celebradas. A continuación, ilustramos esta explicación con el siguiente cuadro.

\begin{tabular}{|c|c|c|c|}
\hline \multicolumn{4}{|c|}{$\begin{array}{l}\text { DIVISIÓN DE LAS ACTAS CAPITULARES PARA LA CLASIFICACIÓN DE LOS DIFERENTES } \\
\text { FENÓMENOS FONÉTICOS }\end{array}$} \\
\hline $\begin{array}{l}\text { GRUPOS DE } \\
\text { SESIONES }\end{array}$ & $\begin{array}{l}\text { CRONOLOGIAA DE } \\
\text { LAS SESIONES }\end{array}$ & $\begin{array}{l}\text { FIRMAS DE LOS } \\
\text { ESCRIBANOS DE } \\
\text { LAS SESIONES }\end{array}$ & $\begin{array}{l}\text { TIPOLOGIA DE LA } \\
\text { ESCRITURA (Cada } \\
\text { sesión) }\end{array}$ \\
\hline $\begin{array}{c}1^{\text {er }} \text { Grupo de sesiones } \\
\text { ( } 11 \text { sesiones })\end{array}$ & $\begin{array}{ll}\text { 1) } & 1600-1605 \\
\text { 1) } & 23 / 06 / 1600 \\
\text { 2) } & 07 / 04 / 1602 \\
\text { 3) } & 11 / 04 / 1602 \\
\text { 4) } & 21 / 04 / 1602 \\
\text { 5) } & 13 / 05 / 1603 \\
\text { 6) } & 15 / 12 / 1604 \\
\text { 7) } & 20 / 12 / 1604 \\
\text { 8) } & 12 / 01 / 1605 \\
\text { 9) } & 24 / 01 / 1605 \\
\text { 10) } & 15 / 02 / 1605 \\
\text { 11) } & 04 / 11 / 1605\end{array}$ & $\begin{array}{c}\text { Jerónimo de morales } \\
\text { escribano mayor del } \\
\text { cabildo }\end{array}$ & $\begin{array}{c}\text { Procesal con caracteres } \\
\text { humanísticos }\end{array}$ \\
\hline $\begin{array}{l}2^{\circ} \text { Grupo de sesiones } \\
\text { ( } 3 \text { sesiones . Una de } \\
\text { ellas separada en el } \\
\text { tiempo, la de } 1615 \text { ) }\end{array}$ & $\begin{array}{ll} & 1605 \\
\text { 1) } & 12 / 12 / 1605 \\
\text { 2) } & 13 / 12 / 1605 \\
& \\
& 1615 \\
\text { 3) } & 04 / 03 / 1615\end{array}$ & $\begin{array}{c}\text { Jerónimo de Morales } \\
\text { escribano mayor del } \\
\text { cabildo }\end{array}$ & Humanística \\
\hline $\begin{array}{l}3^{\text {er }} \text { Grupo de sesiones } \\
\text { (1 sesión) }\end{array}$ & $\begin{array}{c}1609 \\
\text { 1) } 01 / 04 / 1609\end{array}$ & $\begin{array}{l}\text { Cristóbal de Morales } \\
\text { escribano publico }\end{array}$ & Procesal \\
\hline $\begin{array}{l}4^{\circ} \text { Grupo de sesiones } \\
(2 \text { sesiones })\end{array}$ & $\begin{array}{c}1614 \\
\text { 1) } 26 / 08 / 1614 \\
\text { 2) } 09 / 02 / 1614\end{array}$ & $\begin{array}{l}\text { Cristóbal de Morales } \\
\text { escribano publico }\end{array}$ & $\begin{array}{c}\text { Procesal (diferente } \\
\text { modalidad de la } \\
\text { anterior) }\end{array}$ \\
\hline $\begin{array}{c}5^{\circ} \text { Grupo de sesiones } \\
\text { ( } 6 \text { sesiones })\end{array}$ & $\begin{array}{c}\text { 1615-1617 } \\
\text { 1) } 11 / 05 / 1615 \\
\text { 2) } 16 / 05 / 1615 \\
\text { 3) } 30 / 09 / 1615 \\
\text { 4) } 08 / 04 / 1616 \\
\text { 5) } 10 / 06 / 1616 \\
\text { 6) } 03 / 05 / 1617\end{array}$ & $\begin{array}{l}\text { Luis de Morales } \\
\text { escribano del cabildo }\end{array}$ & Procesal encadenada \\
\hline
\end{tabular}


Como hemos señalado con anterioridad, los documentos que vamos a analizar pertenecen a la ciudad de Lucena que se halla situada en la Subbética al Sur de la provincia de Córdoba. Posee esta ciudad una privilegiada situación que la hace estar en el centro geográfico de Andalucía. De este modo, supuso una zona estratégica de luchas entre el reino árabe y cristiano. En 1240 fue conquistada por Fernando III, manteniéndose como frontera, con numerosos y frecuentes cambios de dominio hasta la conquista de Granada. En abril de 1483 se produce el hecho más importante en la historia de esta ciudad: la batalla del arroyo de Martín González en la que D. Diego Fernández de Córdoba derrotó y apresó a Boabdil, último rey de Granada. De este modo, es desde Lucena desde donde parte la reconquista del Reino Granadino. Si consideramos este último dato, podemos pensar que muchos de los fenómenos fonéticos como seseo o aspiración de /-s/ implosiva serían llevados desde estos territorios y también desde tierras sevillanas hasta el citado Reino de Granada. Esto es un asunto que trataremos más adelante.

A continuación, vamos a mostrar los fenómenos fonéticos hallados en las citadas Actas Capitulares. Antes de indicarlos, diremos que se trata de fenómenos en consonancia con las diferentes descripciones fonéticas que se han elaborado a propósito de la lengua castellana del siglo XVII en la zona meridional de la Península Ibérica (Ariza, 1996: 43-79; Cano Aguilar 2004: .825-857; Chamorro, 2001b: 319-328.). De este modo los fenómenos fonéticos más sobresalientes que presentan los documentos estudiados son los siguientes: confusión de sibilantes, aspiración de /-s/ implosiva, velarización, confusión b/v, vacilación a la hora de emplear determinados grupos consonánticos y vacilación en el timbre de las vocales átonas'.

\section{Consonantismo}

\subsection{Confusión de sibilantes}

\subsubsection{Consideraciones teóricas: Definición y cronología del fenómeno}

Comenzamos el análisis fonético de las Actas Capitulares del siglo XVII. Hemos de señalar que trataremos con más profundidad las confusiones de sibilantes, y especialmente los casos de seseo y ceceo hallados ya que es el aspecto más llamativo que presentan estos documentos.

Es importante indicar que la ciudad de Lucena es conocida en la actualidad por ser una zona en la que es mayoritario el fenómeno denominado seseo. Un seseo característico por articularse con la llamada [s] andaluza coronal (Lapesa, 1981:512; Zamora Vicente, 1974: 302).

De este modo, estas actas nos parecieron interesantes para poder aportar algunos datos esclarecedores que pudieran reflejar este fenómeno fonético en etapas históricas anteriores.

Estimamos oportuno antes de comenzar a aportar los datos hallados en estos documentos, recordar que en los reinos de Sevilla y Córdoba, en todo el occidente y el sur de Granada, se consolidó la confusión de las fricativas apicoalveolares con las fricativas dorsodentales procedentes de las antiguas africadas (c o ç y z, respectivamente).

1 No seguiremos el orden tradicional que supone establecer primero el análisis del vocalismo, posteriormente, el del consonantismo ya que en este caso consideramos más interesante este último y, en especial, el apartado de las sibilantes. 
De este modo, con el ensordecimiento de las sibilantes sonoras los cuatro fonemas originarios se redujeron en mayor parte de Andalucía y el dominio Atlántico a uno cuyas variedades articulatorias pueden reducirse a dos tipos fundamentales: dental e interdental, a ellos corresponden las designaciones modernas de seseo y ceceo. En el caso de Lucena, y en la mayor parte del sur de Córdoba y norte de Málaga el único fonema superviviente de la citada confusión, $/ \check{s} /$, adoptó la realización fonética $[\bar{s}]$ coronal andaluza citada anteriormente que en el siglo XVIII se fonologizó.

En cuanto al inicio de este fenómeno fonético, hemos de señalar las opiniones de González Ollé (1988: 347) para el que en el siglo XV, 1425, Mosé Arragel de Guadalajara (traductor, de la Biblia de la Casa de Alba) ya se conocían en Castilla a leoneses, sevillanos y gallegos. Este dato podría hacernos reflexionar ya que cabe la posibilidad de que los andaluces en estas fechas sean reconocidos debido a unas características fónicas (entre ellas puede estar el seseo) o léxicas peculiares. De todos es conocido como en este siglo XV existen juicios y consideraciones desfavorables hacia las manifestaciones linguísticas empleadas en Andalucía, recordemos las burlas de Valdés hacia el propio Nebrija por ser andaluz. Así pues, este testimonio que nos ofrece González Ollé puede hacernos pensar en la existencia del seseo y ceceo en el siglo XV como peculiaridad fonética en Andalucía. El mismo Ariza (1996: 43-79), por su parte, indica que la confusión de sibilantes está presente en el Cancionero de Baena como lo había indicado Menéndez Pidal (1962: 114). No obstante, recientemente Cano Aguilar (2004: 844) sostiene que es en el siglo XVI cuando el fenómeno puede considerarse bien establecido debido a que existen datos de confusiones entre las clases sociales elevadas.

Sin embargo, según autores como Frago (1993: 220-272) o Chamorro (1995: 17-38) el fenómeno de seseo y ceceo se puede adelantar en el tiempo:

Para el primer investigador, desde el siglo XIII ya se puede hablar de las primeras confusiones que nos llevarán en el siglo XV hacia el establecimiento del seseo y ceceo andaluces. Testimonia el trueque de c por ss en Sevilla durante el siglo XIII (1293): suçessores, sosçepçores y soçepçores. Otro trueque es el de $\mathrm{s}$ por c en ensensarios 'incensarios'.

Por otra parte atestigua la igualación ç/z en el Repartimiento de Jerez de la Frontera en torno a 1338: diçen, Luzia y Luçia. Por su parte, el segundo investigador, considera que la confusión de sibilantes ya se detecta en textos latinos de los siglos VIII y IX en casos como mence o sensuram. Incluso, halla ejemplos que manifiestan en territorio andaluz las tempranas confusiones: sierço (Sevilla, 1253) o Medina Çidonia (Arcos de la Frontera, 1268). A la luz de estos datos, Chamorro apuesta por que el seseo y ceceo ya empezaran a consolidarse a fines del siglo XV y principios del XVI. Para demostrar esta hipótesis recurre a un incipiente ceceo encontrado en el manuscrito de La Coronación perteneciente a Juan de Mena en el que figura çegun por 'según'.

\subsubsection{Datos hallados en las Actas Capitulares: seseos y ultracorrecciones}

Con todos estos estudios sobre la cronología del seseo y del ceceo, estamos en disposición de sostener que en el siglo XVII este fenómeno fonético estaría más que consolidado en Lucena. No olvidemos que como señala Menéndez Pidal (1962: 110), el mismo Barahona de Soto, poeta lucentino de 1548 que cursó estudios en Antequera, rima voces con dioses. Este dato es de gran utilidad para poder afirmar que los ejemplos hallados en las actas son sintomáticos y revelan más que una simple confusión de grafías o trueque de fonemas. 
A continuación, mostramos algunos de los ejemplos hallados en las Actas Capitulares estudiadas. Se trata de cuatro vocablos que presentan confusiones que ahora detallamos. Estos vocablos son: procesión, comisión, suceso, intersección. Para ciertos investigadores como Tuten (2003: 215-256) estos casos serían inválidos a la hora de considerarlos como muestras de seseo y ceceo ya que contienen más de una sibilante. Sin embargo, nosotros los consideramos totalmente válidos como muestras del citado fenómeno ya que la persona seseante o ceceante tiene problemas a la hora de su escritura, llegando en ocasiones a introducir ultracorrecciones en algunos casos.

\subsubsection{Casos de procesión, comisión, suceso, intercesión}

Analizamos en primer lugar las distintas manifestaciones escritas del vocablo procesion ${ }^{2}$.

Si consideramos el primer grupo de sesiones ${ }^{3}$, comprobamos que en esta palabra figura siempre la confusión de sibilantes: prosesiones ${ }^{4}$, proseçion $^{5}$, proscecion $^{6}$.

Si tenemos en cuenta el quinto grupo de sesiones el vocablo procesión aparece escrito de las siguientes formas: proceçion ${ }^{7}$, procession ${ }^{8}$. Es llamativo que este amanuense, autor de este quinto grupo de sesiones, en ocasiones sí distinga e indique de forma correcta este vocablo a diferencia del amanuense del primer grupo que siempre emplea esta palabra con las grafías incorrectas.

Para finalizar con este vocablo es preciso señalar que en los demás grupos de sesiones el vocablo aparece escrito correctamente.

En el caso de comisión tan sólo hallamos el siguiente caso perteneciente al primer grupo de sesiones: comiçion ${ }^{9}$. Es preciso señalar que en los demás grupos de sesiones e, incluso, en las restantes sesiones del primero, el vocablo figura escrito de manera correcta.

La palabra suceso tan sólo se confunde por parte del amanuense del cuarto grupo de sesiones. En dichas sesiones el vocablo figura en una de ellas como: cuceso $^{10}$. No obstante en el segundo grupo de sesiones este vocablo aparece escrito de esta forma: succeso ${ }^{11}$. Creemos que la consonante geminada permanece debido a que el amanuense ha sido fiel a la etimología latina, SUCCESUM. En el resto de los grupos el vocablo suceso no se utiliza por parte de los diferentes amanuenses.

Finalmente, analizamos los vocablos intersección e intercesora. Ambos vocablo tan sólo se hallan presentes en el primer grupo de sesiones. $Y$ aparecen escritos de estas formas intersección $^{12}$ e intesesora ${ }^{13}$, respectivamente.

2 Para seguir las explicaciones, es necesario considerar el cuadro expuesto con anterioridad

3 Recuérdese que cada grupo de sesiones pertenecen a un escribano diferente.

4 Prosesiones figura escrito de esta manera en las sesiones de: 07/04/1602 (fol. 51, lin. 20), 11/04/1602 (fol. 54,

lin. 15 y 16 , lin. 16 y 17 , respectivamente).

5 Proseçion figura escrito de esta manera en las sesiones de: 15/12/1604 (fol. 155, lin. 11).

6 Prosecion figura escrito de esta manera en las sesiones de: 15/12/1604 (fol. 155, lin. 18) Nótese que en la misma sesión el mismo escribano escribe de dos formas diferentes el vocablo: proseçion y prosecion.

7 Proceçion: figura escrito en la sesión de $08 / 04 / 1616$ (fol. 216, lin. 10).

8 Procesison: sesiones de 30/09/1615 (fol. 126, lin. 27) y 03/05/1617 (fol. 106, lin. 17).

9 Sesión de 15/12/1604 (fol. 155, lin. 20).

10 Sesión de 26/08/1614 (fol. 358, lin. 18).

11 Sesión de 04/03/1615 (fol. 15, lin. 9).

12 Sesión de 07/04/1602 (fol. 51, lin. 14).

13 Ibídem (fol. 51, lin. 17). 


\subsubsection{Conclusiones}

Las conclusiones a las que llegamos tras el análisis de los datos antes expuestos son las siguientes:

En primer lugar, hemos de decir que si hallamos nueve ejemplos que claramente reflejan confusión de sibilantes es debido posiblemente a que los diferentes amanuenses podrían presentar rasgos como el seseo o el seseo en su variedad lingüística castellana. Además, podríamos aventurarnos a pensar que muchos de estos amanuenses eran lucentinos o de zonas andaluzas seseantes. No obstante, no podemos extraer una conclusión tan categórica de manera tan rápida y no podemos considerar todos los ejemplos hallados de forma conjunta.

De este modo, consideramos al primer grupo de sesiones (1600-1605). Las confusiones pertenecientes a dicho grupo revelan que el amanuense que las escribió debía de ser seseante en virtud de casos como: prosesiones (lo escribe de esta manera hasta tres veces) o intersesora. El resto de los ejemplos revelan que este mismo amanuense debía haber cometido una serie de ultracorrecciones ceceantes y seceantes como: proseçion, prosecion, comiçion o ynterseçion. Así pues, es en el primer grupo de sesiones donde con más claridad se puede analizar el comportamiento que el amanuense posee con respecto a las sibilantes.

Si consideramos el quinto grupo de sesiones (1615-1617), hemos de señalar dos casos: proceçion y procession. Aunque son pocos casos los obtenidos en este grupo, pueden ser sintomáticos para detectar al menos confusión de sibilantes en el amanuense.

Mostramos otro grupo de sesiones, el cuarto (1614), en el que también se halla un ejemplo de confusión de sibilantes como ya hemos señalado con anterioridad. El caso encontrado es: cuceso. Aunque un ejemplo no es suficiente para poder extraer conclusiones en este grupo, no podemos dejarlo pasar ya que casos de otros grupos anteriores pueden hacernos pensar en que el fenómeno pudiera ser una realidad en la Lucena del siglo XVII.

Si tenemos en cuenta todos estos casos, advertimos que no en todos los grupos de sesiones existen ejemplos reveladores de seseo, lo que revela que no todos los amanuenses que escriben estas actas presentan en sus respectivas hablas confusiones de sibilantes. No obstante, el estudio de estos documentos nos ha mostrado casos que sí nos indican la presencia de amanuenses cuyas hablas sí debían presentar un fenómeno como es el denominado seseo y ceceo $^{14}$.

\subsection{Aspiración de /-s/ implosiva}

En las Actas Capitulares estudiadas hallamos dos ejemplos pertenecientes al primer grupo de sesiones (1600-1605) y al mismo amanuense: nueve fiesta ${ }^{15}$ y su casas ${ }^{16}$. Dichos ejemplos nos muestran la falta de la /-s/ implosiva. Hemos de decir que sólo en este grupo es donde hemos hallado esos dos casos, por lo que no podemos afirmar categóricamente que en los documentos estudiados el fenómeno se halle generalizado. Además, tampoco es posible sostener rotundamente que el escribano del primer grupo de sesiones aspire la /-s/

14 Muchos casos de ceceo no son tales, sino que simplemente son muestras de un hablante seseante que en un intento de autocorregirse comete ultracorrecciones deseantes o ceceantes como ocurre con el amanuense del primer grupo de sesiones.

15 Sesión de 15/12/1604 (fol. 155 r., lin.12).

16 Sesión de 13/05/1603 (fol. 31 r., lin. 6). 
implosiva ya que escribe las mismas secuencias con presencia de /-s/: nueve fiestas ${ }^{17}$ y sus casas $^{18}$. De este modo, podemos estar ante un olvido o lapsus calami del mismo. Incluso, si atendemos a las indicaciones de Espinosa Elorza (1997: 65), se puede proponer que estos casos reflejen una mala concordancia por parte del amanuense.

No obstante, el hecho de que estos ejemplos los hallemos en Lucena, localidad en la que actualmente se aspira la /-s/ implosiva, puede hacernos vacilar y llegar a pensar que la falta de esta grafía en los anteriores ejemplos sea debida a una razón concreta y el amanuense no lo haga por mero capricho u olvido. Además, los ejemplos mostrados por Pascual (1998: 391) o Chamorro (2001b:319-328) contribuyen a hacernos reflexionar. De este modo, el primer investigador nos muestra la forma de escribir de una monja, Ana de San Bartolomé nacida en el Sur de Ávila que atestigua la aspiración en una copia realizada del Cántico de San Juan de la Cruz con los siguientes ejemplos: casos de pérdida de $-\mathrm{s}$ (monte, fuerte, ojo, senblante) y de singulares con -s (las manos, hermosuras, mensajeros). Por su parte, el segundo investigador también considera la ausencia de /-s/ como señal de aspiración. Así nos muestra en sus estudios casos de omisión de $/$-s/, esta vez, en posición interior de palabra: Cataños (Cádiz, 1560) o depedidos (Granada, 1506). Incluso, se han hallado ejemplos tempranos de aspiración de /-s/ implosiva en tierras septentrionales de la Península y, así, Frago (1993: 447) atestigua en comarcas leonesas: lo gozos, obtinado, ojos hermoso.

No obstante, existe un nutrido grupo de investigadores, entre ellos, Mondéjar (1991: 199) que considera estos ejemplos inválidos ya que se trata de meros errores grafemático que suponen falta de hábito o impericia de los escribanos a la hora de enfrentarse al lenguaje escrito. Para él lo que se escribe no siempre refleja lo que se pronuncia ya que de lo contrario no existirían las llamadas faltas de ortografía. De este modo, Mondéjar considera (1991: 288-289) que uno de los autores primeros que toman conciencia del fenómeno y lo testimonia gráficamente es, según su opinión, Antonio Machado y Álvarez quien escribe: necesita'h.

Así pues, nos hallamos ante una cuestión difícil de dilucidar. En cierto modo, los ejemplos mostrados de las actas capitulares pueden deberse simplemente a un error o descuido del amanuense que escribe en otras ocasiones las mismas expresiones con la /-s/ implosiva. Por otra parte, podemos llegar a pensar que si el amanuense comete este error es debido a alguna razón porque de lo contrario no se equivocaría al escribir tales ejemplos. Además, el hecho de que en ningún otro grupo de sesiones y, por lo tanto, ningún otro amanuense cometa errores en las mismas expresiones contribuye a que nos cuestionemos si estamos o no ante un fenómeno cuyo origen, según Pascual (2000: 77-93), no fue la zona meridional de la Península.

\subsection{Velarización}

Este trabajo ha revelado que la prepalatal fricativa sonora, $/ \check{z} /$, se ha ensordecido puesto que grafías como x, j, y g ya representan al fonema velar fricativo sordo. Es decir, que hallamos diferentes grafías referidas a un mismo sonido que desde el paladar se ha ido retrayendo hacia posiciones más próximas al velo del paladar. De la misma manera lo piensa el propio Lapesa (1981: 371-372) para el que el aflojamiento de las sibilantes africadas y su posterior ensordecimiento contribuyeron a que la grafía $x$ confluyera con $g \mathrm{y} j$, respectivamente. Este 
investigador (1981: 378) establece el siglo XVI como siglo de la generalización y establecimiento del fenómeno, aunque sostiene que ya Nebrija y Juan de Vergara equiparan el sonido de $\mathrm{x}$ al de la $\mathrm{x}$ griega.

La conclusión que extraemos de todo este panorama sobre la cronología de la velarización y el valor de las distintas grafías: $\mathrm{x}, \mathrm{j}$, g es la siguiente: Podemos proponer el siglo XV y XVI como siglos en los que se generaliza la velarización procedente de la prepalatal fricativa sorda ya que nuestras actas demuestran que el fenómeno de la velarización estaba completamente establecido en el XVII.

Nuestro trabajo aporta datos interesantes con respecto a este fenómeno ya que todos los grupos que incluyen las diferentes sesiones nos ofrecen ejemplos. De este modo, en el primer grupo (1600-1605) de sesiones para representar a la velar fricativa se emplean: dixere ${ }^{19}$, trajo $^{20}$, ximemes $^{21}$. Si analizamos el segundo grupo de sesiones (1605) también hallamos la alternancia entre las grafías $x$ y $j$ que representan a un mismo sonido velar: juntaron ${ }^{22}$, exerçer $^{23}$. No obstante, en el tercer grupo (1609) sólo hallamos la $j$ para representar al citado fonema: rrejidor ${ }^{24}$; en el cuarto grupo (1614) tan sólo hallamos la x: rexidores ${ }^{25}$, rexidor $^{26}$; y en el quinto (1615-1617), la g: regidores ${ }^{27}$.

\section{4. $\mathrm{B} / \mathrm{V}$}

El fenómeno de confusión entre b/v nos lo presenta Ariza (1994: 50) perfectamente definido "b sonora oclusiva se había neutralizado con la fricativa $b$ que provenía de $/ \mathrm{u} /[\ldots]$ " Esta / $\mathrm{u} /$ hemos de tener en cuenta que se consonantizó al crearse un haz de palatales en el latín hablado. En dicho haz se integró la semivocal palatal /i/ por lo que /u/ queda aislado con lo que se produce su consonantización e integración en el haz de labiales. Por tanto, podemos decir que $/ \mathrm{u} /$ evoluciona a $/ \mathrm{b} /$.

En cuanto a la procedencia del fenómeno, hemos de decir que el fenómeno parece nacer en tierras septentrionales de la Península, concretamente de Burgos. Con respecto a la parte meridional de la Península, de todos es conocido que esta confusión entre b y v llegó con más retraso a Andalucía. La igualación entre estos dos fonemas fue avanzando desde el norte hacia el sur propiciada por el traslado de la Corte a Madrid en el año 1562 lo cual supuso que gentes procedentes de tierras septentrionales se establecieran en la nueva capital. Este cambio trajo consigo otro cambio en cuanto a la norma fonológica, no olvidemos que hasta ese momento la norma lingüística más prestigiosa era la toledana. Comprobamos, pues, como un cambio de situación político-administrativa influyó enormemente en la norma fonético-fonológica de dicha época trayendo consigo la confusión entre $b / v$ iniciada en centurias anteriores.

19 Sesión de 23/06/1600 (fol. 188, lin. 37).

20 Sesión de 24/01/1605 (fol. 160r., lin.13)ß.

21 Sesión de 04/11/1605 (fol. 24, lin. 11 y 12).

22 Sesión de 12/12/1605 (fol. 32, lin. 21).

23 Ibídem (fol. 32v., lin. 20).

24 Sesión de 01/04/1609 (fol. 52 v., lin. 8 y 9 ).

25 Sesión de 26/08/1614 (fol. 358, lin. 12).

26 Sesión de 09/02/1614 (fol. 7, lin. 1).

27 Sesión de 11/05/1615 (fol. 21, lin. 26 y 27). 
Si continuamos la explicación de la expansión del fenómeno en el sur, hemos de decir que Mateo Alemán sostiene que no existe confusión entre b/v en Andalucía. Sin embargo, en 1631 Juan de Robles ya no sabe distinguir. Lo que sucede es que las incipientes igualaciones entre $b / v$ aparecerían primero en ámbitos socioculturales inferiores y no serían atestiguados por gramáticos y escritores que, en ocasiones, no reflejan la manera de hablar real sino aquella que se debía de seguir según las pertinentes prescripciones lingüísticas.

La [v] estaba vigente en la Andalucía del siglo XVI y así dicha articulación fue trasladada a América, aunque fue sustituida pronto por la bilabial fricativa del español estándar.

De este modo, ya en el siglo XVII la confusión b/v estaba completamente instalada en Andalucía, así lo atestiguan los amanuenses de las Actas Capitulares estudiadas. En todas las sesiones se atestigua este tipo de confusión: trabajo ${ }^{28}$, cauildo $^{29}$, debocion ${ }^{30}$, vastante $e^{31}$, benidero ${ }^{32}$.

\subsection{Grupos consonánticos}

Las Actas Capitulares estudiadas revelan que no se respetan ciertos grupos consonánticos como: -mn-, -ct-, -cc-, -pt- o -pc-. Este fenómeno no es privativo de las citadas actas sino que de todos es sabido que en el Siglo de Oro existen vacilaciones a la hora de incluirlos en los diferentes vocablos, incluso se produce esta situación en la Literatura de la época. Cano Aguilar (2003: 852) indica que gramáticos como Correas, Ximénez Patón o Nebrija no reconocían algunos grupos consonánticos como propios. Así, durante el Siglo de Oro las formas reducidas se empleaban en la Literatura y en el habla popular sin estar estigmatizadas.

En cuanto a las causas que podrían haber provocado la ausencia de determinados grupos consonánticos, el propio Lapesa (1981: 390) sostiene que las dudas surgen al adaptar ciertas palabras del latín al español clásico. De este modo, la conservación de ciertas secuencias consonánticas ha podido deberse a la influencia de la escuela o la misma Academia. Lloyd (1993: 557-559) profundiza aún más en su explicación y cree que las vacilaciones son debidas a la tendencia a debilitar las consonantes finales de sílaba en nuestro idioma.

Si analizamos los ejemplos hallados en nuestro trabajo, llegamos a estas conclusiones:

Grupo -mn-: El amanuense que escribe las sesiones pertenecientes al segundo grupo (1605) simplemente emplea un vocablo que contiene la pareja consonántica -mn-: solem$n e^{33}$. No obstante, en el tercer grupo de sesiones (1609) el amanuense la única vez que emplea el nombre solemnidad lo hace simplificando la pareja -mn- : solenidad ${ }^{34}$. El propio Lapesa (1981: 390) señala que en el Siglo de Oro es frecuente que gramáticos como Ximenez Patón empleara este vocablo sin el citado grupo consonántico.

Grupo -ct-: En las actas hallamos vocablos como doctor, efecto y octubre a los que les falta dicho grupo. Así en el tercer grupo (1609) de sesiones figura: dotor ${ }^{35}$ y en el quinto grupo (1615-1617) de sesiones se hallan: efeto y $^{36}$ otubre $^{37}$. Se constata pues, que los ama-

28 ler grupo: Sesión de 15/02/1605 (fol. 164 r., lin. 9).

$292^{\circ}$ grupo: Sesión de 12/12/1605 (fol. 32 r., lin. 21).

30 3er grupo: sesión de 01/04/1609 (fol. 52 v., lin. 2).

$314^{\circ}$ grupo: sesión de 26/08/1614 (fol. 358 v., lin. 6).

$325^{\circ}$ grupo: sesión de $11 / 05 / 1615$ (fol. 52v., lin. 36).

33 Sesión de 04/03/1615 (fol. 15, lin. 9).

34 bidem (fol. 52 v., lin. 2).

35 Sesión de 01/04/1609 (fol. 52, lin. 18).

36 Sesiones: 30/09/1615 (fol. 126 r., lin. 1), 08/04/1616 (fol. 216 r., lin. 11) y 10/06/1616 (fol. 236 r., lin. 30).

37 Ibidem (fol. 126r. lin. 8 y 10 ). 
nuenses de estos dos grupos de sesiones no incluía la consonante velar implosiva en los diferentes vocablos que debían llevarla ya que al escribir todos los vocablos que llevan este grupo consonántico siempre la suprimen.

No faltan estudios que traten este grupo consonántico. Así, Torreblanca (1980: 7) comenta casos como de ottubre y otubre y advierte que el español moderno

experimenta un proceso general de lenición articulatoria de las consonantes en cualquier posición silábica: caída de fricativas sonoras, sonorización de las sordas, fricativización de oclusivas y aspiración de algunas oclusivas

Si nos fijamos en los casos de dotor y otubre creemos que se trata de vocablos en los que ya se ha superado la fase de geminación consonántica ya que la evolución de los mismos en la mitad meridional de la Península sería: doctor $>$ dohtor $>$ doctor $>$ dotor y octubre $>$ ohtubre $>$ ottubre $>$ otubre, respectivamente. Estas evoluciones vienen avaladas por estudios de Mondéjar (1991: 253-263) que en un esclarecedor artículo que nos habla del carácter bifonemático de los grupos consonánticos geminados. Opina que el español carece de sonidos geminados, mientras que su variedad andaluza emplea dichos sonidos como rasgos distintivos de rendimiento funcional. Mondéjar (1991: 313) establece el inicio de la asimilación consonántica de los grupos latinos -ct- y -pt- en el latín tardío del centro y sur de Italia. Aporta ejemplos de la articulación de -ct- en andaluz: nohtturno, pahtto, tahtto o notturno, patto, tatto. Se produce, pues, como podemos advertir, un debilitamiento de la implosiva velar sorda agrupada con la dental. Así Chamorro (2001a: 265-272) nos presenta pruebas de geminación consonántica a finales del siglo XV y principios del XVI halladas en Sevilla, Cádiz, Granada, Guadix, Loja y Méjico: dottor, dottas, ottubre, aspetto y pato 'pacto'.

Grupos -cc- y -cp-: Finalmente tratamos los grupos -cc- y -cp- en el quinto grupo de sesiones (1615-1617). En dicho grupo hallamos los siguientes vocablos en los que se detecta la ausencia de la consonante velar y bilabial, respectivamente: elecion ${ }^{38}$, aceten ${ }^{39}$, conçeçion $^{40}$.

\section{Vocalismo}

\subsection{Vacilación en el timbre de vocales átonas}

En las Actas Capitulares hallamos ejemplos que nos muestran una vacilación bastante frecuente. No en vano en la lengua del Siglo de Oro dichas vacilaciones son abundantes como señala el mismo Menéndez Pidal (1977: 66-67) para el que el asunto de las vocales inacentuadas en nuestra lengua era debido a que las dos vocales palatales e, i y las dos velares o, u se hallan próximas entre sí, sobre todo si no van acentuadas. De este modo, esta situación provocó que en el siglo XVI existieran vacilaciones en el lenguaje literario ya que las vocales protónicas no estaban fijadas admitiéndose así: vanedad, envernar, cobrir, etc.

Existen otros investigadores como el propio Mondéjar (1991: 204) que no sólo se limita a presentar las vacilaciones citadas sino que intenta presentar diferentes causas que las ex- 
pliquen: Inestabilidad de timbre de la vocal inacentuada, asimilación o disimilación, cambio analógico.o cruce de palabras o términos. Según Muñoz Garrigós (1998: 94) la vacilación de átonas se debe a una "diferente distribución de alófonos al tomar como espejo la referencia de las acentuadas".

A modo de conclusión, diremos que este fenómeno lo podemos encontrar desde la etapa medieval; aunque nuestro trabajo revela ejemplos procedentes de Lucena (Córdoba) de principios del siglo XVII. Estimamos que la vacilación más que por disimilación, analogía o efecto de una yod se produce ya que las vocales inacentuadas se hallan menos definidas en cuanto a su timbre, lo que contribuye a que se confundan entre las palatales e /i y las velares $\mathrm{o} / \mathrm{u}$. Estas confusiones las encontramos primero en una lengua literaria no fijada aún en el Siglo de Oro y, en nuestro caso, en unas Actas Capitulares. A medida que avancemos en el siglo XVII este tipo de confusiones quedarán relegadas al lenguaje popular y a las clases sociales menos cultas.

Finalmente, destacamos los ejemplos hallados en nuestro trabajo.

En el primer grupo de sesiones no existe vacilación en el timbre de las vocales átonas (1600-1605): ministriles ${ }^{41}$ Advertimos esta situación porque en el segundo grupo de sesiones (1605) este vocablo figura escrito como menestriles $^{42}$, lo que indica cierta vacilación que en el primer grupo no se produce.

En el tercer grupo de sesiones (1609) no existe vacilación en el timbre de las vocales átonas y así hallamos perfectamente escrita una palabra que podría prestarse a ciertas dudas por parte del amanuense y sin embargo no comete error alguno en ella: dilijencias ${ }^{43}$.

Es en el último grupo (1615-1617) en el que se produce el mayor número de vacilaciones y así hallamos: prevelejio ${ }^{44}$ y pusible ${ }^{45}$ por una parte; $y$ eleccion $^{46}$, benidero ${ }^{47}$, por otra.

\section{Conclusión}

En estas Actas Capitulares de Lucena (1600-1617) hemos estudiado una serie de fenómenos: confusión de sibilantes, aspiración de /-s/ implosiva, velarización, confusión $\mathrm{b} / \mathrm{v}$, ciertos grupos consonánticos como -mn-, -ct- o-cp- y, por último, la vacilación en el timbre de las vocales átonas. El estudio de todos estos fenómenos fonéticos revela un estado de lengua prototípico del siglo XVII.

No obstante, hemos de ser cautelosos a la hora de extraer conclusiones en lo que a la confusión de sibilantes y la aspiración de /-s/ implosiva se refiere ya que no todos los amanuenses autores de las veintidós sesiones estudiadas los reflejan en su escritura. Si consideramos la confusión de sibilantes, posiblemente los datos hallados nos inclinan a pensar que el amanuense del primer grupo de sesiones podría presentar en su habla seseo. En cuanto a la aspiración de /-s/ implosiva, los ejemplos hallados en este primer grupo de sesiones se prestan a una doble interpretación: los ejemplos hallados pueden deberse a un descuido o

\footnotetext{
41 Sesiones de 23/06/1600 (fol, 188, lin. 36) y de 15/12/1604 (fol. 155, lin. 6).

42 Sesión de 12/12/1605 (fol. 32, lin. 13).

43 Sesión de 01/04/1609 (fol. 52 v, lin. 30).

44 Sesión de 30/09/1615 (fol. 126, lin. 3) 11/05/1615.

45 Sesión de 08/04/161 (fol. 236, lin. 12).

46 Sesión de 16/05/1615 (fol. 56v., lin. 36).

47 Sesión 11/05/1615 (fol. 52v., lin. 2).
} 
despiste del amanuense o bien, por el contrario, si emplea expresiones en las que se detecta la ausencia de este sonido es porque su habla se caracteriza por este fenómeno.

Por todo lo estudiado en este trabajo, en el resto de las actas es difícil llegar a conclusiones categóricas en lo que a seseo y aspiración de /-s/implosiva se refiere ya que no todos los amanuenses reflejan estos fenómenos en su escritura. No obstante, estos documentos reflejan en algunos de sus folios estos dos fenómenos que actualmente tienen vigencia en Lucena.

Para el resto de los fenómenos fonéticos estudiados, sí que podemos encontrarnos más seguros ya que en todos los grupos de sesiones se presenta la confusión de b/v, la velarización, la vacilación a la hora de emplear algunos grupos consonánticos y la vacilación en el timbre de vocales átonas.

\section{Referencias bibliográficas}

Ariza Viguera, M. (1994): Sobre fonética histórica del español. Madrid, Arco Libros.

Ariza Viguera, M. (1996): "Reflexiones sobre la evolución del sistema consonántico en los Siglos de Oro", Actas del III Congreso Internacional de Historia de la Lengua Española, I. Madrid, Arco Libros, 1996, págs. 43-79.

Cano Aguilar, R. (1988): El español a través de los tiempos. Madrid, Arco Libros.

Cano Aguilar, R. (2004): "Cambios en la fonología del español durante los siglos XVI y XVII". En Rafael Cano (coord.): Historia de la lengua española. Barcelona, Ariel, págs. 825-857.

Chamorro, J.M. (1995): "Problemas de fonética histórica del andaluz". En Manuel Galeote y Antonio Moreno Ayora (eds.): Hablas cordobesas y literatura andaluza. Granada, Universidad de Granada, págs. 17-38.

Chamorro Martínez, J.M. (2001a): "Cambios fonológicos en las hablas del mediodía peninsular", RFE, LXXXI, págs. 319-328.

Chamorro Martínez, J.M. (2001b): "En torno a algunos aspectos del español meridional y ultramarino de los siglos XVI y XVII", Actas del V Congreso Internacional de "El español de América", (CD), Burgos, págs. 265-272.

Frago, J.A. (1993): Historia de las hablas andaluzas. Madrid, Arco Libros, págs. 220-272.

González Ollé, F. (1988): "Primeras noticias y valoraciones del andaluz", BRAE, LXVIII, págs. 347-385.

Lapesa Melgar, R. (1981): Historia de la Lengua Española. Madrid, Gredos.

Lapesa Melgar, R. (1985): "Sobre el ceceo y seseo andaluces", Estudios de Historia Lingüistica española, Madrid, págs. 67-94.

Lapesa Melgar, R. (1992): “El español llevado a América”. En César Hernández Alonso (ed.): Historia y presente del español de América. Madrid, págs. 11-24.

Lloyd, P. (1993): Del latín al español. Madrid, Gredos.

Menéndez Pidal, R. (1962): "Sevilla frente a Madrid", Estructuralismo e Historia III, Miscelánea y homenaje a André Martinet. La Laguna, págs. 99-165.

Menéndez Pidal, R. (1977): Manual de Gramática Histórica Española. Madrid, Espasa-Calpe.

Mondéjar Cumpián, J. (1991): Dialectología Andaluza. Estudios. Historia, fonética, fonologia, lexicología, metodología, onomasiología, comentario filológico. Granada, Los Libros del Caballero del verde Gabán, Editorial Don Quijote.

Muñoz Garrigós, J. (1998): "Aproximación a la lengua española del siglo de Oro. El Epistolario de Fray Luis de Granada" en Actas del IV Congreso Internacional de Historia de la Lengua Española, I. Logroño, Universidad de La Rioja, págs. 91-101.

Torreblanca, M. (1980): "La sílaba española y su evolución fonética", Thesaurus, Boletín del Instituto Caro y cuervo, XXXV, págs. 1-10.

Tuten, D. (2004): Koenization in medieval Spanish. Berlín, Nueva York; Mouton, de Gruyter; 2003. Zamora Vicente, A. (1974): Dialectología española. Madrid, Gredos, Biblioteca Románica Hispánica. 